\title{
TARIFF CONSIDERATIONS FOR MICRO-GRIDS IN SUB-SAHARAN AFRICA
}

Tim Reber, Sam Booth, Dylan Cutler, Xiangkun Li and James Salasovich | National Renewable Energy Laboratory

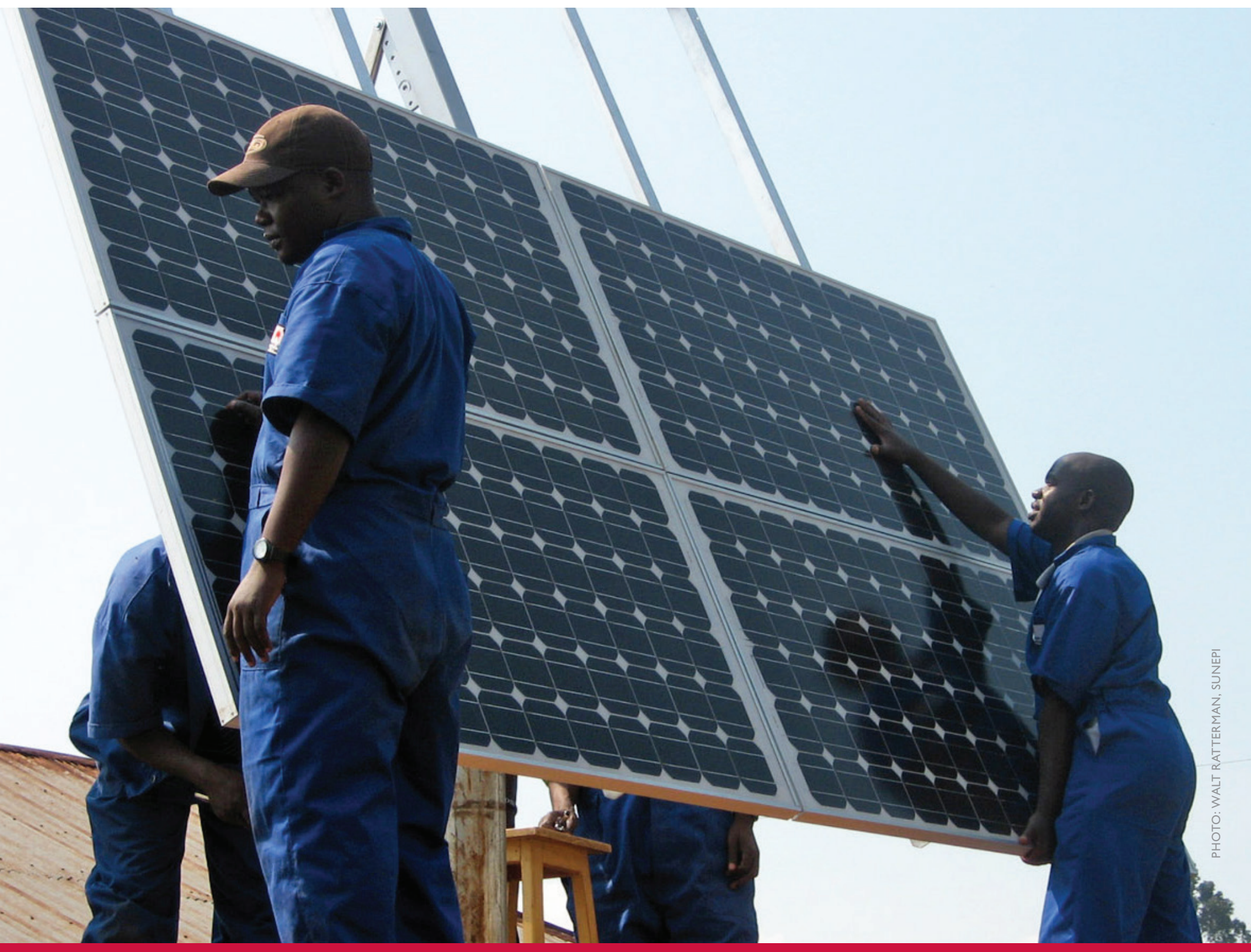

NREL/TP-7A40-69044

February 2018

Contract No. DE-AC36-08GO28308 


\section{NOTICE}

This report was prepared as an account of work sponsored by an agency of the United States government. Neither the United States government nor any agency thereof, nor any of their employees, makes any warranty, express or implied, or assumes any legal liability or responsibility for the accuracy, completeness, or usefulness of any information, apparatus, product, or process disclosed, or represents that its use would not infringe privately owned rights. Reference herein to any specific commercial product, process, or service by trade name, trademark, manufacturer, or otherwise does not necessarily constitute or imply its endorsement, recommendation, or favoring by the United States government or any agency thereof. The views and opinions of authors expressed herein do not necessarily state or reflect those of the United States government or any agency thereof, including the United States Agency for International Development.

This manuscript has been authored by employees of the Alliance for Sustainable Energy, LLC ("Alliance") under Contract No. DE-AC36-08GO28308 with the U.S. Department of Energy ("DOE").

The tables and figures in this report are limited to use in this report only and are not to be further disseminated or used without the permission of the sources cited.

NREL prints on paper that contains recycled content. 


\section{Acknowledgments}

The National Renewable Energy Laboratory (NREL) thanks Power Africa Beyond the Grid for its guidance and input throughout this work, specifically Katrina Pielli and the Beyond Grid Transaction Advisory Team. Abishek Bharadwaj, Peter Weston, and the entire team at Energy 4 Impact also deserve thanks for their valuable input. Many thanks to members of the micro-grid development community who offered data, feedback, and time. Finally, Ian-Baring Gould at NREL deserves great thanks for his continued guidance and support. 


\section{Summary}

This report discusses of some of the key drivers and considerations that policymakers and decisionmakers face when deciding if and how to regulate electricity tariffs for micro-grids. Specifically, we frame the discussion around tariff options at two different ends of a regulatory spectrum: mandating some variety of national (uniform) tariff versus allowing micro-grid developers and operators to set fully costreflective tariffs that may vary from site to site. We analyze the benefits and drawbacks of these and other options. We also discuss how cross-subsidies and other transitional forms of regulation may offer a regulatory "middle ground" that can help balance the often competing goals of providing price control on electricity service in the name of social good while providing a means for investors to achieve sufficient returns on their investment to attract the necessary capital financing to the market. NREL's REopt tool is used to model a representative micro-grid system and the resulting levelized cost of electricity (LCOE), which is used to put context and scale around these tariff questions. This simple analysis offers an estimate of the gap between current tariff regimes and the tariffs that would allow developers to recover costs to attract further investment. This analysis also provides insight into the potential scale of subsidies or other grants that may be required to enable micro-grid development under current regulatory structures. In nearly all cases, a hybrid micro-grid configuration incorporating solar photovoltaics (PV), batteries and diesel proved to be the lowest-cost option when compared to diesel or solar PV alone. However, the estimated LCOE's of these systems are still on the order of \$US $0.70 / \mathrm{kWh}$ - well above the typical subsidized tariffs charged by many utilities - creating a cost gap that may be addressed through effective policy and regulation. Potential options for addressing this gap while balancing the needs of all stakeholders are explored, including extending subsidies for micro-grids to charge national tariffs, allowing more lightly regulated cost-reflective tariffs, or other compromise approaches based on the size of each micro-grid. 


\section{Table of Contents}

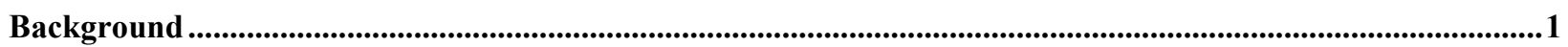

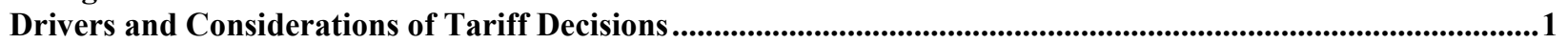

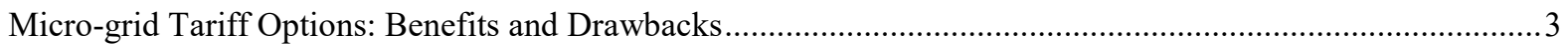

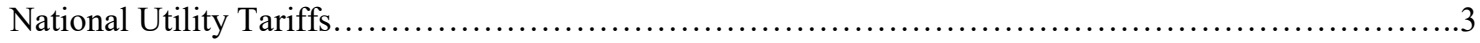

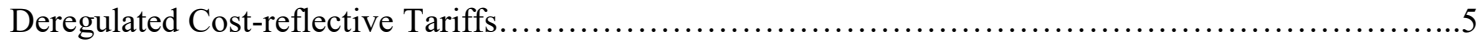

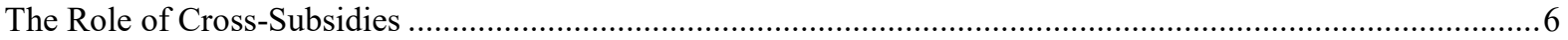

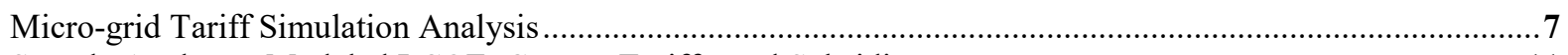

Sample Analyses: Modeled LCOE, Current Tariffs, and Subsidies ............................................................... 11

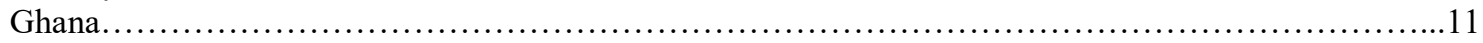

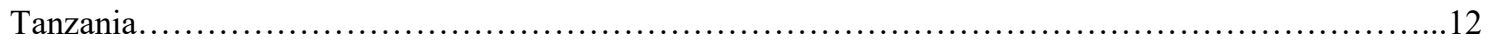

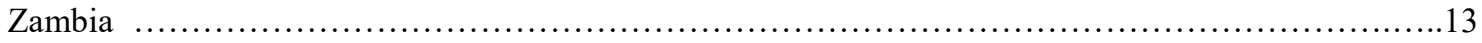

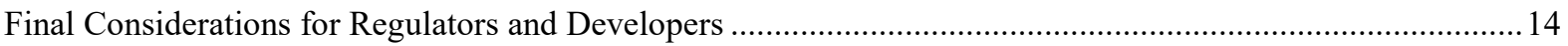

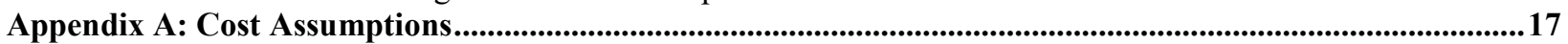

Appendix B: Load Profile Development .....................................................................................................................19

Appendix C: LCOE Sensitivity Analysis Using REopt ........................................................................................21

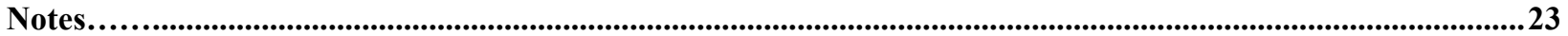

\section{List of Figures}

Figure 1. Electrical load profile comparison ..................................................................................................................10

Figure 2. LCOE for different system types across different geographical regions................................................11

Figure B-1. Normalized electrical load profile comparison .........................................................................................20

Figure C-1. The impact of load shapes and quality of service on micro-grid LCOE (Tanzania example).........22

\section{List of Tables}

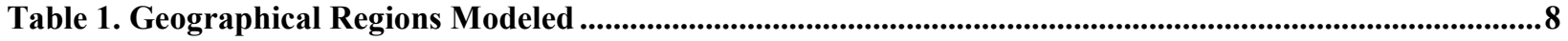

Table 2. Main Cost Assumptions and Economic Parameters .........................................................................................9

\section{List of Boxes}

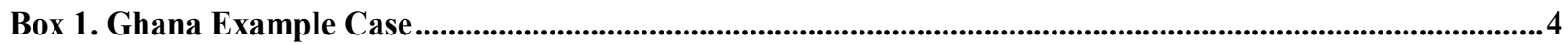

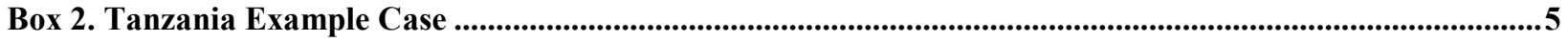

Box 3. Grid Extension Comparison Zambia ..............................................................................................................6 


\section{Background}

Across the planet, an estimated 1.2 billion people lack access to modern electricity services. As global efforts to bring electricity to these unserved populations accelerate, estimates suggest that more than half of these people - some 750 million - will be most quickly and effectively reached via remote, off-grid power solutions such as isolated micro-grids. ${ }^{1}$ Recent years have seen a significant uptick in interest from national governments, international donors, and private investment firms in developing isolated microgrids as a reliable and cost-effective means to reach unelectrified communities. Indeed, nearly half of investment in electrification efforts over the coming decades will likely be in support of isolated standalone and micro-grid solutions - creating a global micro-grid investment need of up to USD 20 billion annually. $^{2}$

As developing country governments and donors alone are likely unable to achieve these levels of investment, micro-grid developers must be able to attract private debt and equity financing to sustain the scale of deployment required to achieve global electrification goals. For this to happen, micro-grids must be perceived as commercially viable endeavors capable of providing a reasonable return for investorssomething that is typically contingent on collecting tariffs that ensure revenues cover costs and provide an attractive payback.

However, in the context of developing countries, setting commercially viable tariffs is often not as straightforward an issue as one might expect. While micro-grids are often the least-cost solution for providing power to remote, rural population centers, on a per-kilowatt-hour $(\mathrm{kWh})$ basis they often deliver power that is more expensive than what existing utility grid-tied customers in urban areas may be paying. Large (typically state-owned) utilities can average their costs to serve each individual customer across a wide customer base, allowing them to charge uniform tariffs that effectively cross-subsidize customers that are more expensive to serve with revenue from those that are cheaper. In many cases, these tariffs may still be further subsidized directly by the government or through donor-funded infrastructure projects, allowing state-owned utilities to charge tariffs that are well below their average cost of service or to subsidize the cost of adding new connections by waiving connection fees for new customers. Thus, the tariff that an individual utility customer-existing or new-pays does not reflect the full cost to the utility of serving that customer but rather the grid-wide average. ${ }^{3}$

However, when micro-grids are adopted, this status quo can give rise to some difficult —and often political - questions about how to determine fair and appropriate electricity tariffs and who should be responsible for such decisions. Should regulators or developers have the ultimate say? Should tariffs be tied to existing utility rates or some nationwide average, or should developers be free to determine their own tariff structures? This brief aims to shed light on some of these questions by reviewing the complex factors at work when making decisions around micro-grid tariffs and then comparing modeled tariff projections with current electricity rates in several sub-Saharan African contexts.

\section{Drivers and Considerations of Tariff Decisions}

An informed discussion about micro-grid tariffs first begins with an understanding of the key drivers and motivators underlying these tariffs, which vary across diverse stakeholders within the larger power sector. The Quality Assurance Framework for Mini-Grids ${ }^{4}$ outlines six micro-grid stakeholder groups and their roles in detail (government ministries, regulators, investors, system developers, micro-utilities, and 
customers) ${ }^{*}$, but in regard to tariff-setting, these roles can generally be distilled at a high level down to three primary groups:

1. Governments - represent energy ministries, regulators, national treasuries, and the like, and are responsible for setting policy and creating and enforcing regulation that balances stakeholders' diverse interests; may also include national utilities.

2. Developers - manage the planning, construction, commissioning, operation, and revenuecollecting for micro-grids, and are typically accountable to members of the investment (or donor) community that have financially backed their projects (and may also have a set of requirements or conditions of their own).

3. Customers - typically do not have direct control ${ }^{\dagger}$ over tariffs, but their concerns and subsequent decisions influence the considerations of both governments and developers. For example, their perceptions of and willingness to pay tariffs and fees can have political impacts for governments as well as real impacts on system design, customer connection rates, load growth, and financing considerations.

Electricity is generally viewed as a public good, and thus from a government perspective, equity and fairness are paramount concerns. Many African governments have established uniform national electricity tariffs in order to ensure not only fairness across customers but also affordability. ${ }^{5}$ Often these national tariffs are set at a rate below what utilities must charge to cover their capital and operational costs, creating a need for ongoing subsidy assistance to cover the gap and ensure continued provision of utility services. This can be a politically attractive setup, but can also drain national treasuries and distort markets such that it is impossible for those not receiving comparable levels of subsidies to remain commercially viable (e.g., private micro-grid developers). Because many governments may struggle with subsidy shortfalls, subsidies can act as a disincentive for utilities to expand energy services, as they lose more money with each new connection. Some governments subsidize transmission infrastructure in order to expand connections, but this, too, artificially lowers the perceived cost of providing energy services to rural populations. Minimizing subsidies and applying them equally can be an important goal, but one that, in many developing countries, is only secondary to the goal of quickly and cheaply expanding capacity and access to meet rapidly growing energy demand and support economic growth.

Additionally, governments may seek to maintain long-term flexibility so that they can be responsive to changing domestic needs and larger global trends, and hence may be resistant to signing long-term power purchase agreements (PPAs) that may affect future expansion decision. As many utilities in developing countries are revenue-based state-owned enterprises, this same desire may also inhibit the issuance of long-term concessions for micro-grid developers. The utility may also be reticent to make any firm commitments regarding the absorption of established micro-grids into the larger grid in the event of eventual utility extension. This uncertainty is further exacerbated by political sensitivities that deter governments from openly admitting that the national grid may not reach some communities for many years, if ever, thus sustaining false expectations of grid connection that can deter both developers and customers.

On the other side, developers are primarily concerned with recouping expenses and seek confidence in their long-term ability to provide returns to investors. When considering cost recovery, developers

\footnotetext{
${ }^{*}$ Sometimes these groups can be one in the same- - e.g., the system developer may also serve as the micro-utility operator once the system is commissioned.

${ }^{\dagger}$ In some cases, customers may have stronger say regarding tariffs. For example, in Tanzania, customers in areas where tariffs are not regulated are given the opportunity to disapprove of newly proposed tariffs. The threshold to force tariff review is $15 \%$ of customers filing complaints to the Tanzanian Energy and Water Utilities Regulatory Authority (EWURA).
} 
consider not only initial capital but also ongoing operational costs. Developers are ultimately accountable to their financial backers - who may be private equity investors, commercial lenders, or members of the donor or development bank community. Regardless of who backs the project, the expectation is the same: deliver the agreed-upon level of service and financial returns.

Long-term business model sustainability is paramount to developers' ability to make good on their commitments to investors. The payback period for a new micro-grid can often exceed five years, ${ }^{6}$ so certainty and longevity in the political and regulatory environment are critical factors for long-term business model sustainability. Developers and investors want to be confident that any agreements, tariff approvals, or subsidies on which their financial and operational viability depends will be valid for the duration - ideally at least 10 years $^{7}$ or more - to ensure not only cost-recovery but also profitability. Otherwise, key dependencies of their business model may suddenly become annulled. Similarly, developers desire confidence that they will be able to sell to the grid at the agreed-upon tariff or be otherwise compensated for their assets in the event that the national grid does eventually expand into their service territory.

\section{Micro-grid Tariff Options: Benefits and Drawbacks}

Within this complex environment of competing priorities and drivers, policymakers and regulators are tasked with setting fair and effective tariff guidelines for micro-grids. At the highest level, there are two general tariff schemes, which could be considered opposite ends of a diverse spectrum: uniform national utility tariffs and deregulated cost-reflective tariffs.

\section{National Utility Tariffs}

Under a national utility tariff scheme, customers are generally charged a uniform tariff regardless of whether they are connected to an urban utility grid, a rural utility grid, or an isolated micro-grid. The intent of this type of tariff is to provide a sense of fairness and equality across all customers - a position that can be highly politically favorable. Usually national tariffs are tied directly to utility grid rates or may be based on a utility's cost-of-service analysis. These rates may be cross-subsidized or directly subsidized by the government to keep electricity prices low and affordable.

While often perceived as equitable to customers, national tariffs are in practice often the most restrictive for micro-grid developers as it forces them to compete with rates far below what they would otherwise charge to recoup expenses. In a recent survey of African power industry stakeholders, two-thirds of respondents indicated that the inability to recover the costs of new power projects under current tariff schemes is the biggest barrier to more rapid power development in sub-Saharan Africa. ${ }^{8}$ 


\section{Box 1. Ghana Example Case}

Ghana presents an interesting West African example of the issues surrounding tariff setting and subsidies. In 2017, Power Africa conducted a policy and regulatory assessment in Ghana, which serves as the basis for this example. In Ghana, electricity rates are set by the government and privately owned micro-grids are expected to follow these rates. The rates vary from a low "lifeline" tariff rate of $33.56 \mathrm{Ghp} / \mathrm{kilowatt-hour} \mathrm{(kWh)} \mathrm{(USD} \mathrm{0.077)} \mathrm{with} \mathrm{rates} \mathrm{increasing} \mathrm{with} \mathrm{consumption,} \mathrm{with} \mathrm{the}$ highest residential rate being $97.09 \mathrm{Ghp/kWh}$ (USD 0.233) and the highest commercial rate being $162.51 \mathrm{Ghp} / \mathrm{kWh}$ (USD 0.37). Even at the highest rates, it may be a challenge for private micro-grid developers in Ghana to build financially viable systems; this becomes especially challenging at the lifeline tariff rates under which many first-time off-grid customers would likely fall. It is possible for Ghanaian developers to appeal to the public utility regulatory commission (PURC) to apply for a waiver to charge higher rates, but this requires appearing before the commission and approval on a case-bycase basis and results in high transaction costs and limited scalability. Allowing developers to charge national rates often requires significant subsidies from the government of Ghana. A number of microgrids operating in Ghana currently face tariff challenges-for example, the Ghana Energy Development and Access Project (GEDAP) has funded 5 micro-grid projects, but the tariffs being collected do not even fully cover operational costs. Current net subsidy requirements range between 5.82 and 55.73 Ghp (USD 0.01-0.13) per kWh per month, depending on the tariff category. A private developer operating these micro-grids would need to charge even higher rates to fund repayments of system capital costs and operating costs. ${ }^{9}$

Another potential drawback of national tariffs is that they can often have a market-distorting effect whereby customers - particularly those in remote regions - do not understand the utility's true cost to provide their individual service, which can set unrealistic expectations about how much they should pay for power and exacerbate tariff-setting challenges in remote areas. Unlike most large utilities, micro-grids often lack a large, high-density urban client that can be used to cross-subsidize a costlier rural population. Although the tariff may be nationally uniform, the costs of providing power are not, which greatly distorts the market for rural energy providers.

Furthermore, many large, utility-related capital expenses - such as the installation of new powergeneration equipment, transmission line expansion, or major plant upgrades - are heavily subsidized through direct investment or long-term subprime loans. These costs are typically not reflected in national tariffs.

Ultimately, national tariffs are often simply too low to attract investors to develop micro-grids in rural regions, leaving remote customers relying on utilities to extend the grid. However, in many cases, energy regulators consider only the current cost of service delivery when setting national tariff rates and do not consider the added costs of new investment, meaning many utilities in sub-Saharan Africa cannot afford to extend the grid or add capacity while charging existing national tariffs without incurring significant losses or requiring additional direct subsidies. ${ }^{10^{*}}$ Therefore, remote consumers continue to be left in the dark. Subsidies, which are discussed further below, can be one mechanism to help close the investment gap for micro-grid developers.

\footnotetext{
*As one example, in 2016, Tanzania Electric Supply Company Limited (TANESCO) asked the Tanzanian government for a rate hike of $18.9 \%$ to cover ongoing losses. In response, EWURA granted TANESCO a rate hike of $8.5 \%$ - less than half of what was requested - which the president then completely blocked in January of the following year, thus perpetuating the cycle of utility losses that not only inhibit needed transmission and capacity expansion but also risk the utility's long-term financial solvency.
} 


\section{Box 2. Tanzania Example Case}

In 2009, the Tanzanian government launched a new Small Power Producer (SPP) program. Under the program, SPPs operating in isolated power systems (e.g. micro-grids) of less than 1 megawatt (MW) are exempt from national licensing requirements. SPPs operating at less than $100 \mathrm{~kW}$ are exempt from both licensing requirements and the tariff approval typically required by EWURA. In addition, the SPP program sets two tariffs: one for SPPs selling to Tanzania's main grid and a second, higher feed-in tariff for SPPs operating in isolated micro-grids. The higher tariff is determined by calculating TANESCO's average avoided cost of building and running a diesel plant in these remote, unelectrified communities. Under the SPP program, TANESCO still often owns and bears the cost of local distribution infrastructure for most micro-grids, though SPPs may also construct and operate their own micro-grid distribution infrastructure with ad-hoc, cost-reflective tariff approval. As of 2016, the standardized micro-grid feed-in tariff for SPP's operating in TANESCO-owned micro-grids was 477 Tanzanian Shillings (USD 0.26) —nearly double the standard national SPP tariff of 242 Tanzanian Shillings (USD 0.13). These SPP tariffs are adjusted annually to account for macroeconomic changes in the country, but floor price provisions included in standardized SPP power purchase agreements provide certainty of SPP tariffs for new developers. Tanzania's pro-micro-grid enabling environment has sparked new private-sector interest in micro-grids, attracting dozens of new businesses to the space who have developed more than 50 new micro-grids (mostly solar photovoltaic [PV] or bioenergy) since the SPP framework entered into force. ${ }^{11}$

\section{Deregulated Cost-reflective Tariffs}

On the other end of the spectrum are what are referred to as "cost-reflective" tariffs. Under such schemes, developers of micro-grids are free to set their own tariffs at a rate that is high enough to allow them to recover their costs - both capital and operational. In many cases, these cost-reflective tariffs may also be subject to regulatory approval. Generally, cost-reflective tariffs will be higher than rates charged to existing grid customers, but they are still determined through an implicit agreement between customers and micro-grid operators such that customers are willing and able to pay (else the micro-grid development will fail). As one saying goes, "People want electricity more than they want low tariffs - particularly in remote, rural areas where they may have no other options." ${ }^{12}$ Often the cost-reflective rate that would be charged by a micro-grid developer, though higher than utility grid rates, will still be lower than what unconnected customers are ultimately paying for energy services in the form of kerosene, candles, batteries, or other fuels - not to mention the other negative socioeconomic consequences associated with low-quality, unreliable energy access. ${ }^{13}$

Cost-reflective tariffs can more effectively attract micro-grid investment by providing a viable means for developers to recoup costs and investors to secure returns, and can thus increase the overall speed of deployment of new micro-grids. Notably, this can also reduce the financial burden on already stressed national utilities, as each new utility connection often incurs additional losses for the utility. These higher cost-reflective tariffs may also decrease over time once initial capital expenses have been fully paid back - in some cases even prior to eventual grid connection.

However, despite their advantages, cost-reflective tariff schemes are not without drawbacks - some of which are perceived and some of which are real. Governments may fear that remote customers connected to micro-grids could become upset that they pay more than those tied to national grids, which could lead to reduced revenue collection rates in addition to political consequences. Cost-reflective tariffs can also sharpen questions about what happens if the national grid ever does reach communities currently served by cost-reflective micro-grids. Does the higher cost-reflective tariff remain, potentially causing discontent among these customers, or do they adopt the lower grid rate, effectively destroying the micro-grid operator's business model (unless it becomes subsidized by the government or the operator is otherwise compensated for its assets)? In practice, however, this highly subsidized utility model will likely not be financially sustainable in the long run, so it is unclear for how long utility tariffs will remain low 
compared to micro-grid tariffs or utilities will be able to continue absorbing the costs of extending the grid at all.

Between these two ends of the spectrum, there are a range of compromises and other options, such as (but not limited to):

- Allowing cost-reflective tariffs only after explicit and thorough regulatory review and approval, potentially with a subsidy of initial energy consumption by specific user classes to address customers at the bottom of the socioeconomic spectrum

- Allowing cost-reflective tariffs for micro-grids but providing grants or subsidies to reduce the cost of power from those systems to one that is more consistent with the tariff charged to grid-tied customers

- Regulator-determined tariffs based on the full costs of building and operating a specific micro-grid, including costs of financing and required returns and profit margins (often referred to as a "cost-plus" methodology)

- National utility tariff schemes that account for the higher cost of micro-grids by charging higher rates to all customers (including those tied to the grid) to balance the cost of micro-grids

- Setting size thresholds and regulating tariffs differently for micro-grids of different capacities - e.g., fully deregulated cost-reflective tariffs for small systems, an intermediate level of tariff regulation for medium-scale systems, and a uniform national tariff for the largest systems.

Box 3. Grid Extension Comparison Zambia

When analyzing micro-grid costs and subsidies, it is necessary to also discuss providing energy access through grid extension. In this scenario, the costs of building the necessary transmission and distribution infrastructure can be significant and are almost always subsidized by the national government through state-owned utilities or by development institutions. In Zambia, the rural electrification rate is 3.3\%. Energy Minister David Mabumba has stated a government target of electrifying $51 \%$ of the households in rural areas by 2030 at an approximate investment cost of USD 50 million per year. The government is primarily focused on grid-extension projects and has implemented 160 grid-extension projects, 421 solar-home systems, and one solar micro-grid through the rural electrification agency. Costs per connection vary by factors such as distance from the grid, voltage, and terrain, but a recent project funded by a European Union energy facility provided approximately 7,000 connections at a cost of USD 9.9 million, or roughly USD 1,400 per connection. This estimate is similar to nearby Rwanda, where average costs varied between USD 880 and 2,000 per connection. A recent report from the Rocky Mountain Institute found that a micro-grid was more cost-effective if a village was at least 4 kilometers $(\mathrm{km})$ from the grid. For Zambia, it could be wise for the government to consider policy changes that clearly establish a framework for micro-grid tariffs to help expand the micro-grid market and provide project opportunities, as micro-grids may be the most cost-effective option in many areas of rural Zambia. ${ }^{14}$

\section{The Role of Cross-Subsidies}

Cross-subsidization of tariffs can be another viable and proven mechanism to balance a sense of equity and fairness for different customers while increasing the ability of power suppliers (large utilities or micro-grid developers) to more effectively recoup their costs. At its core, a cross-subsidy charges one group of customers a higher rate than they would otherwise be charged and uses the surplus revenue to subsidize lower rates for another group that is below their individual cost of service. These crosssubsidies should not be confused with the different components of a typical utility tariff schedule, which aims to ensure that individual customers are charged appropriately to reflect their true impact on the cost of operating the grid - also referred to as a blended tariff structure. In practice, a simple form of cross- 
subsidization could be achieved through creative use of these existing blended tariff components, which may include:

- Customer class: Different types of customers (e.g., commercial, residential, or community/government) are charged different flat rates. Generally, commercial consumers would be charged more to cross-subsidize lower rates for residential customers to meet basic living needs.

- Quantity-of-use: The marginal tariff rate increases in a stepwise manner as a customer uses more energy. ${ }^{*}$ Additional revenue from higher-intensity users can cross-subsidize lower rates for a basic level of subsistence use across all customers.

- Capacity-based: Similar to a quantity of use tariff, but rather than charging different marginal rates based on use, customers pay a flat tariff rate based on their maximum peak consumption.

- Time-of-use: Different rates are charged depending on the time at which power is used, with higher rates being charged at times when demand is highest to allow lower rates at low-demand times. This practice can be used to try to shift peaks and valleys in demand and have a smoothing effect on demand profiles, which can simplify system operations and increase overall efficiency.

Within the context of micro-grids, several cross-subsidization schemes could be applied. For example, a customer-class tariff could be used to charge a higher rate to a large anchor consumer (such as a telecommunications tower) with slightly lower rates for businesses and the lowest rates for low-income households. Alternatively, a quantity-of-use or capacity-based tariff could be charged to ensure that all consumers are provided a subsistence level of electricity at an affordable rate (i.e. a lifeline tariff), with heavier consumers cross-subsidizing that low rate.

Alternatively, different tariffs could be applied to different levels of service quality, e.g. as defined in the Quality Assurance Framework for Mini-Grids. ${ }^{15}$ In this case, customers that demand the highest quality of service could pay more to cross-subsidize lower rates for a basic level and quality of service for lowerincome customers. Yet another option may be to cross-subsidize micro-grid customers altogether by charging higher rates to grid-tied consumers. This could be done either through a simple direct markup for grid consumers or in a slightly more nuanced manner. For example, a quantity-of-use tariff could be charged to all customers across the entire power system (both grid-tied and micro-grid consumers), with excess revenue from high-intensity industrial consumers connected to the grid used to cross-subsidize tariffs for micro-grids. This tariff results in more closely aligned prices for micro-grid and grid consumers. Cross-subsidization can thus help ensure that costs are spread more equitably across customers while still offering a mechanism to ensure that a minimum level of electricity access is available at low rates to meet basic living needs - for example by charging a higher rate to heavier users or those that require the highest quality service levels. Of course, such tariff schemes are often more difficult to administer and may require more advanced power monitoring and consumer metering capabilities, which could increase costs (despite overall declining price trends in such equipment), so it is important that necessary provisions be put in place during the system design phase. Furthermore, crosssubsidies that place undue burden on high-energy users could run the risk of driving larger consumers to invest in rooftop solar PV systems or other onsite generation, so any such mechanisms must be designed carefully with such considerations in mind.

\footnotetext{
${ }^{*}$ Note that the type of quantity-of-use tariff described here is the reverse of how quantity-of-use tariffs are typically applied in most markets, where larger consumers are in fact charged a lower rate than smaller customers due to the economies of scale associated with their bulk purchasing. However, in these markets, basic access to electricity is generally not a concern. The more socially minded quantity-of-use tariff explained here could be used to ensure a basic subsistence level of affordable electricity access to everyone.
} 


\section{Micro-grid Tariff Simulation Analysis}

To gain a better sense of potential cost-reflective tariffs for African micro-grids, NREL conducted costbased modeling of representative micro-grid systems using their REopt tool. REopt is a techno-economic decision support model used to determine the optimal selection, sizing, and dispatch strategy of candidate technologies such that energy goals are achieved at a minimum life-cycle cost. ${ }^{16}$ The modeled LCOE for these representative micro-grids can be used as a rough approximation for the magnitude of costreflective tariffs that may be charged. This allows a ballpark comparison of cost-reflective tariffs against existing national tariffs and helps illustrate the scale of subsidy that could make projects commercially viable. This provides only a general approximation, as real tariff calculations may differ from these simplified LCOE calculations - for example, by using connection fees or other flat surcharges to recoup some costs (thus decreasing the per-kWh tariff that must be charged), calculating shorter payback timelines (thus increasing the per-kWh tariff that must be charged) or structuring tariffs to decrease over time so as to enable capital payback early on while alleviating consumer concerns of being locked in to high tariff rates indefinitely. A host of other variable factors, such as differences in the rates of inflation, fuel price escalation, and financing costs - which are only approximated here - make detailed financial calculations and accurate long-term comparisons challenging.

Three system types were analyzed across three geographical regions. The representative micro-grid systems considered include diesel-only, solar-battery, and solar-battery-diesel generation systems. These were selected as they are currently the most widely applicable and rapidly growing system types (microhydro is not considered here due to its relatively favorable economics in the limited locations where it can be deployed). The defining characteristics of each modeled region are summarized in Table 1 and the key cost assumptions are stated in Table 2. These assumptions were based on NREL internal data, published reports, ${ }^{17}$ and multiple consultations with local industry participants and stakeholders. See Appendix A for a complete list of assumptions. For this analysis, we attempted to create a comprehensive representative cost model based on the most recent median costs. However, it should be noted that there is a wide range of installed cost estimates for micro-grids in Africa from USD 1.40/watt (W) to over USD $12.00 / \mathrm{W},{ }^{18}$ which may depend on a range of factors such as country, transport distances, technology selection, import tariffs, and quality warranties.

Table 1. Geographical Regions Modeled

\begin{tabular}{|l|lll|} 
Region & East Africa & West Africa & Southern Africa \\
\hline Representative country & Tanzania & Ghana & Zambia \\
\hline Average solar resource $^{19}$ & $6.1 \mathrm{kWh} / \mathrm{m}^{2} /$ day & $5.1 \mathrm{kWh} / \mathrm{m}^{2} /$ day & $5.3 \mathrm{kWh} / \mathrm{m}^{2} /$ day \\
\hline Current fuel price (USD) & $3.20 /$ gallon $^{20}$ & $3.59 /$ gallon $^{21}$ & $4.39 / \mathrm{gallon}^{22}$ \\
\hline
\end{tabular}


Table 2. Main Cost Assumptions and Economic Parameters

\begin{tabular}{|llll|}
\hline & Low & Medium & High \\
\hline Installed PV costs ${ }^{*}$ (USD) & $1,400 / \mathrm{kWp}$ & $1,800 / \mathrm{kWp}$ & $2,200 / \mathrm{kWp}$ \\
\hline Lead-acid battery costs (USD) & $300 / \mathrm{kWh}$ & $400 / \mathrm{kWh}$ & $500 / \mathrm{kWh}$ \\
\hline Inverter and charge controller costs (USD) & $600 / \mathrm{kW}$ & $900 / \mathrm{kW}$ & $1,200 / \mathrm{kW}$ \\
\hline Generator costs (USD) & $400 / \mathrm{kW}$ & \\
\hline Operations and maintenance (O\&M) costs & $2 \%$ of capital expenditure \\
\hline Distribution network costs (USD) & $5,500 / \mathrm{km}$ \\
\hline Soft costs (USD) & \multicolumn{3}{l}{} \\
\hline Discount rate $^{\ddagger}$ & $\sim 3,800 /$ year for given system size \\
\hline
\end{tabular}

Micro-grid load timing and magnitude can have a large impact on costs. To complete this LCOE analysis, NREL developed an annual hourly load profile for a representative African village micro-grid based on a combination of bottom-up estimates and actual system data published by PowerGen, ${ }^{23}$ a leading renewable energy and micro-grid developer in East Africa. A bottom-up approach based on the typical electrical devices found in homes was used to estimate the magnitudes of electrical load profiles, assuming a village of 100 residential households with a business/community load composed of two small shops and one school. To generate the shape of the load profile it was assumed residences use modest amounts of electricity during the daytime and significantly more in the evening, while businesses and community centers use electricity primarily throughout the daytime hours. The residential and business/community electrical load profiles that NREL developed were then combined into a single load profile to represent an entire micro-grid.

This bottom-up load profile was then compared to 11 load profile shapes from actual micro-grids in rural Kenya and Tanzania developed by PowerGen after normalizing to the mean hourly load at each site. Figure 1 shows a comparison of the electrical load profiles for the PowerGen micro-grids along with the NREL bottom-up load profile. The scenarios shown from the PowerGen dataset include the average of all 11 micro-grids in Kenya and Tanzania along with example business-heavy and residential-heavy microgrid load profiles. The total estimated community annual consumption using the NREL bottom-up methodology was $19,711 \mathrm{kWh}$ per annum, with a peak demand of roughly $5.7 \mathrm{~kW}$. The design size required to meet this demand profile would be roughly $28 \mathrm{kWp}$ for a PV-battery only system, ${ }^{\S}$ or $6 \mathrm{kWp}$

\footnotetext{
* Units of USD / kilowatt-peak (kWp). This cost includes structures, wiring, and other costs. See Appendix A for details.

${ }^{\dagger}$ Includes site visits, feasibility studies, surveying, system design, permitting and licensing, approvals, agreements, and customer acquisition.

* A 10\% discount rate was assumed as a baseline based on feedback from local developers and consultants. However, discount rates can vary quite significantly across Africa and may be higher than this in some instances. This may be further compounded by currency risk factors. A simple sensitivity analysis indicates that increasing the discount rate by $50 \%$ (i.e. from $10 \%$ to $15 \%$ ) results in LCOEs that may be between $5-20 \%$ higher.

$\S$ The apparently oversized nature of the PV-battery only system is because the model optimizes system size to always carry $100 \%$ of the load - including through potentially long periods of poor weather. Thus, the model has no choice but to pick a large-enough system to get through the worst stretches of cloudy weather without dropping load.
} 
of PV matched with a 7-kW diesel generator for a hybrid system. Appendix B presents a more detailed discussion of the load profile development. ${ }^{*}$

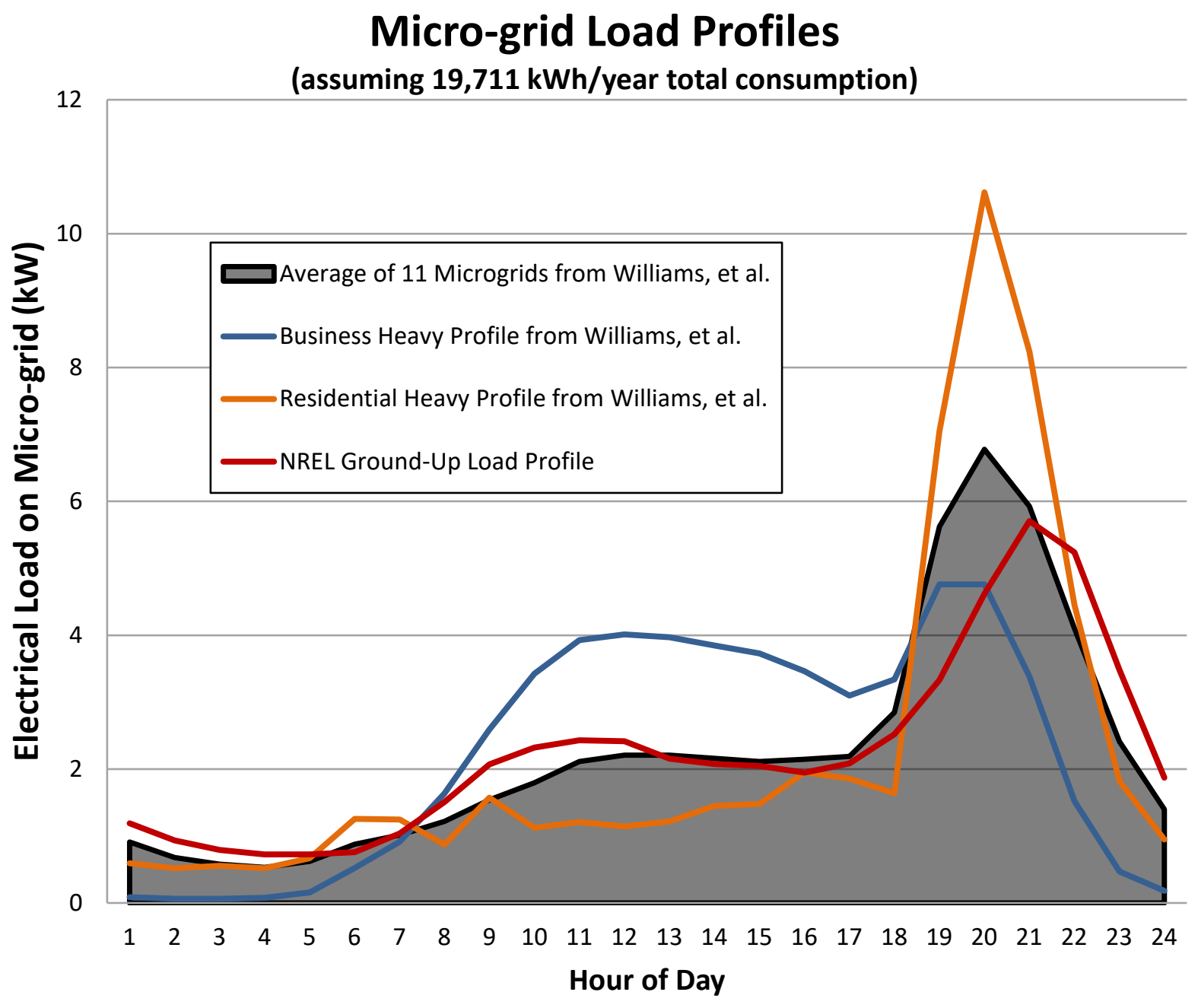

Figure 1. Electrical load profile comparison ${ }^{24}$

Using the bottom-up load profile, three cost points were analyzed for each system type in each geographic region based on low, medium, and high price estimates for current installed PV costs and lead-acid battery systems. Figure 2 shows the LCOE results for each system modeled. The analysis suggests that across all three regions, a hybrid system based on a combination of solar PV, battery storage, and diesel generation is the lowest-cost option, achieving estimated LCOEs for power generation of around USD $0.74-0.86 / \mathrm{kWh}$ and lowering the cost of electricity by roughly USD $0.06-0.12$ per $\mathrm{kWh}$ as compared to a diesel-only micro-grid. Appendix C shows an analysis of LCOE's sensitivity to various factors, including the planned reliability of the system (e.g., portion of load met) and the ratio of commercial to residential loads. ${ }^{\dagger}$

\footnotetext{
* A companion tool is available online allowing users to further explore load profile development and assumptions. Visit: https://cleanenergysolutions.org/qaf

${ }^{\dagger}$ An online companion tool allows users to further explore the REopt LCOE modelling results. Visit: https://cleanenergysolutions.org/qaf
} 


\section{Modeled Micro-grid LCOE for Representative System (assuming median renewable energy costs)}

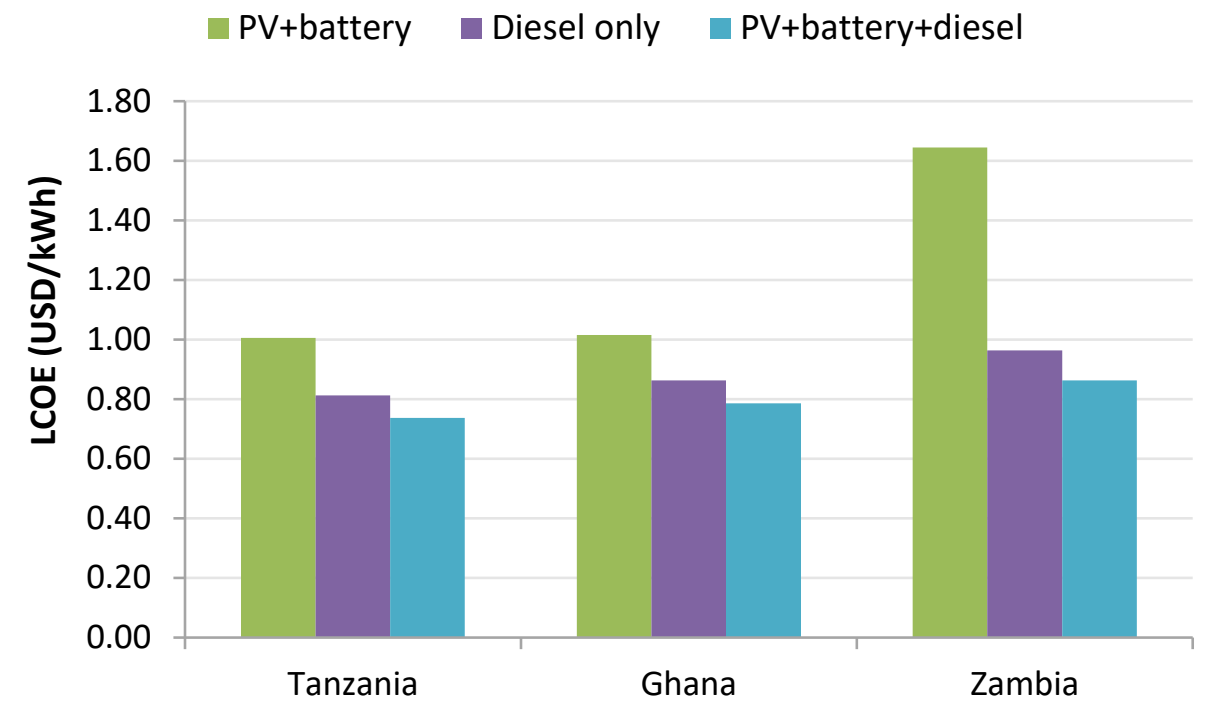

Figure 2. LCOE for different system types across different geographical regions*

Though the micro-grid LCOEs presented in Figure 2 may at first appear high, a recent International Finance Corporation analysis suggested that, on average, households in unelectrified communities in East Africa may already be paying "implied tariffs" of USD 1.75/kWh for low-quality energy from kerosene and candles ${ }^{25}$ - more than double the micro-grid LCOEs estimated here. Furthermore, in many rural contexts the actual cost per $\mathrm{kWh}$ may be less of a consideration than what a household or business is able to do with the electricity. For example, recent advances in low-cost, ultra-efficient appliances for off-grid applications now allow consumers to do more with a single $\mathrm{kWh}$ of electricity than was previously possible.

\section{Sample Analyses: Modeled LCOE, Current Tariffs, and Subsidies}

In order to provide a rough sense of the difference between these simulated micro-grid LCOEs and existing tariffs and the scale of subsidies that could be required to support significant micro-grid deployment in Africa, the modeled LCOEs were compared to three real case studies presented in this article: Ghana, Tanzania, and Zambia. ${ }^{\dagger}$ These countries were selected for their geographic variety (West, East, and Southern Africa, respectively) and differences in their approaches to micro-grid and tariff regulation.

\section{Ghana}

Initial estimates by Power Africa indicate that rural electrification in Ghana is less than $50 \%$ and that $46 \%$ of the country's population lives in rural areas, which equates to roughly 10 million people and 2 million households without access to electricity. ${ }^{26}$ Micro-grids are a key option for the government of Ghana to provide access to electricity to the unelectrified portions of the country, particularly populations in rural

\footnotetext{
* The PV-plus-battery system costs in Zambia are significantly higher than in Tanzania and Ghana due to higher temporal variability in the Zambian solar resource profile.

$\dagger$ These comparisons are based on current tariff schemes and hence do not explicitly account for factors such as inflation, depreciation, or fuel price escalation apart from if and how they may already be factors considered in making national tariff determinations.
} 
areas or on islands where traditional grid extension is not cost-effective. To help frame the order of magnitude of subsidies that may be required in Ghana, some rough estimates were developed using electrification data and NREL's REopt analysis modeling for Ghana. For a typical 100-household village, the cost to supply power from a hybrid PV-battery-diesel system would be between USD 0.75 and 0.80 per $\mathrm{kWh}$. If existing national tariff rates (see Box 1) are charged, a subsidy requirement of roughly USD 0.40 to 0.70 per $\mathrm{kWh}$ would be required to cover the developer's revenue gap, depending on the specific system LCOE cost and the specific tariff selected for comparison. A typical 100-household micro-grid in sub-Saharan Africa would use roughly $20,000 \mathrm{kWh}$ per year, or $400,000 \mathrm{kWh}$ of power sold over a 20 year lifetime. For a single micro-grid system, subsidies would be between USD 8,000 and 14,000 annually, or between USD 160,000 and 280,000 over the system's lifetime. Assuming 1 million households - or roughly $50 \%$ of the current unelectrified population-could be powered with this type of isolated system, this would equate to 10,000 micro-grids of the size and type simulated here. If each system operated in this subsidized manner, the annual subsidy requirements from the government of Ghana would be between USD 80 million and 140 million, and the lifetime subsidy requirements would be between USD 1.6 billion to 2.8 billion. ${ }^{*}$ These annual subsidies represent less than $0.4 \%$ of Ghana's current annual GDP of USD 42.5 billion, but still roughly double the government's current subsidy to the Volta River Authority utility. While the government of Ghana does run a deficit, it could be feasible for the country to support the magnitude of subsidy required, but they would need to determine the priority of these projects relative to other alternatives for government investment. As a comparison, $0.4 \%$ of GDP is on par with subsidy levels in other countries-Tanzania, for example, provided $0.3 \%$ of its national GDP in the form of energy subsidies in 2014 , and prior to that offered as much as $1 \%$ of GDP. ${ }^{27}$

\section{Tanzania}

In Tanzania, the lowest estimated LCOE is approximately USD $0.74 / \mathrm{kWh}$ for a PV-diesel hybrid system. Under Tanzania's current Small Power Producer (SPP) tariff framework, a $\sim 7 \mathrm{~kW}$ system like the one modeled would be exempt from tariff approval due to its small size and hence would be free to charge the cost-reflective tariff of USD $0.74 / \mathrm{kWh}$. With some simple assumptions, we can estimate the potential scale of this tariff scheme's overall benefit to the Tanzanian government by comparing the modeled small-system cost-recovery tariff of USD $0.74 / \mathrm{kWh}$ with Tanzania's SPP micro-grid tariff rate of USD $0.26 / \mathrm{kWh}$ for intermediate-size systems (i.e., $100 \mathrm{~kW}$ to $1,000 \mathrm{~kW}$; see Box 2). If Tanzania's SPP tariff framework required systems less than $100 \mathrm{~kW}$ to also meet the approved micro-grid tariff, then a subsidy of approximately USD $0.50 / \mathrm{kWh}$ would be required to make these small micro-grid projects commercially viable or TANESCO would have to share the cost of constructing and operating the distribution infrastructure. This theoretical subsidy requirement would amount to roughly USD 10,000 per year for a single 100-household village micro-grid or USD 200,000 over the 20-year lifetime of the system - an average annual subsidy of USD 1,400 per $\mathrm{kW}$ installed per year for small PV-diesel hybrid systems.

Since the SPP program was first implemented, 16 small $(<100 \mathrm{~kW})$ solar PV or solar-diesel hybrid microgrids have been deployed in Tanzania, with an average system size of just over $25 \mathrm{~kW} .{ }^{28}$ The exact tariff that these systems charge is not available, but assuming that their tariff rates are close to the REoptmodeled LCOE, we can extrapolate the subsidy that would have been required to support these systems had there been no tariff exemption for small micro-grids under the SPP framework. This would have been about USD 35,000 per year for each of the systems, around USD 560,000 per year to support all 16 micro-grids, or over USD 1.1 million over the combined lifetime of all 16 small solar-diesel hybrid micro-grids. Under the SPP tariff framework, these systems were exempt from charging the approved

\footnotetext{
${ }^{*}$ These estimates do not factor in the revenue-generating effects of increased economic activity and job creation that can be associated with electrification or any benefits associated with reduced kerosene and fossil fuel imports - both of which can lead to increased revenues for governments that can offset the cost of subsidies.
} 
micro-grid tariff, so the government of Tanzania will instead likely save this estimated USD 1.1 million in avoided subsidies because it allows cost-reflective tariffs for small systems.

Extrapolating this further into the future, an estimated 450,000 additional households will need to be connected for Tanzania to increase electricity access from $25 \%$ today to $50 \%$ by 2025 . If just $10 \%$ of these new connections will be served by small solar PV and/or hybrid micro-grids, roughly 450 new micro-grids would be required. With an estimated lifetime subsidy savings of USD 200,000 per 100household system, the government of Tanzania could stand to save more than USD 90 million in avoided subsidies as a result of the SPP tariff approval exemption for small micro-grids. For comparison, the Tanzanian Rural Energy Agency has offered connection subsidies of USD 300-600 as part of the latest call for proposals under its results-based financing mechanism - amounting to a subsidy of USD 30,00060,000 for a 100 -household system. However, the specific tariffs and other fee structures that are being proposed under this new mechanism, as well as relevant cost-sharing and other subsidy and grant support, are not clear, making it difficult to parse out the precise tariff that customers may ultimately pay.

\section{Zambia}

Zambia has some of the lowest electricity prices in Africa, including a lifeline tariff of 0.15 Zambian Kwacha/kWh (USD $\sim 0.02 / \mathrm{kWh}$ ) for residential customers that use less than $200 \mathrm{kWh}$ per month. ${ }^{29}$ At this consumption level, all residential customers in the representative load profile that NREL modeled would fall under this "lifeline" tariff. Commercial customers are expected to pay $0.54 \mathrm{Kwacha}$ per kWh (USD $\sim 0.06 / \mathrm{kWh}) .{ }^{30}$ Assuming that, similar to our representative system, roughly $70 \%$ of micro-grid consumption is residential and $30 \%$ is commercial, the average rate across a small Zambian micro-grid would be about USD $0.03 / \mathrm{kWh}$. Given that the lowest-estimated micro-grid LCOE in Zambia is USD $0.84 / \mathrm{kWh}$, the low national tariff rates would necessitate a potential subsidy of more than USD $0.80 / \mathrm{kWh}$ to make the micro-grid commercially viable. For a single 100 -household system consuming 20,000 $\mathrm{kWh} /$ year, this would amount to an annual subsidy of USD 16,000 per year or USD 320,000 over the 20year lifetime of the system. This is equal to an estimated subsidy of USD 3,200 per household connected via micro-grid, more than double the estimated USD 1,400 per connection required to connect customers via grid extension (see Box 3). However, the cost of grid extension will increase dramatically as customers further away from the grid are connected, while the cost of micro-grids will remain relatively constant regardless of distance from the grid. Therefore, there will be a point at which micro-grid electrification becomes cheaper than grid extension from the perspective of overall government investment or subsidy required per connection. Yet ascertaining the precise distance from the grid at which micro-grids become cheaper to subsidize than grid extension remains elusive. As a starting point, however, the Rocky Mountain Institute has suggested that a distance of $4 \mathrm{~km}$ or more from the grid may be an appropriate threshold (see Box 3). ${ }^{31}$

These three short analyses aim not to inform policy but only to illustrate the relative size of the gap between existing tariffs and estimated costs of micro-grids and to provide a rough idea of the scale of subsidies that may be required to close the gap if new policy and tariff regulation are not adopted to address this gap. The primary conclusion from this exercise is that any mass deployment of micro-grids to achieve significant advances in energy access will require either:

1. Significant increases in allowable tariff rates (e.g. cost-reflective tariffs); or

2. Large-scale subsidies or other financial support for micro-grid developers and operators.

Exactly which of these courses of action is most appropriate (including the possibility of a combination of the two) and how best to implement that course will depend on a given country's context and starting point and will require a far more detailed review process. However, several general considerations are offered below that can shed some light on how to begin addressing this question. 


\section{Final Considerations for Regulators and Developers}

Policymakers and decision makers face difficult questions and complex tradeoffs when considering if, how, and to what degree to regulate micro-grid tariffs. This is especially pertinent when considering micro-grids in the context of more centralized options to supply energy services to rural populations, most of which receive different forms of preferential treatment. Historically, the approach in many countries has been conservative in that regulations err on the side of over-regulation or tariffs that are set too low and hence stifle the market for investment in rural energy development - both grid expansion and new micro-grids. Ultimately, every government needs to determine the approach that will work best within its own unique context. However, from the lessons and analysis presented here we can distill a few general considerations that may help guide policymakers and decision makers as they evaluate options for implementing effective micro-grid tariff structures to electrify remote areas. These considerations fall along three overall trends: (1) a "lightly regulated" cost-reflective tariff, (2) national tariffs with significant subsidy allocation, and (3) a mixed approach that could combine various tariff and subsidy elements based on certain system characteristics such as capacity or the makeup of the consumer base and ability to pay.

The first approach is what could be considered a "lightly regulated" cost-reflective tariff, which may be an effective means to adequately balance the concerns of both governments and developers. Under such a scheme, developers could set their own tariffs, with review and approval from regulators, if desired, primarily to ensure basic technical and safety standards are met. Regulators responsible for reviewing and approving these cost-reflective tariffs would use only the most basic technical criteria to ensure that tariff approval does not risk becoming a bottleneck that impedes new development. Alternatively, this could take the form of a "cost-plus" tariff calculation in which the regulator determines the tariff for each individual micro-grid based on a thorough accounting of the developer's full costs (both capital and operational; hard and soft) as well as required investor returns and profit margins. Additionally, these tariff approvals would be guaranteed for a long enough duration — at least as long as the payback period, ideally 10-plus years - and incorporate appropriate cost-indexing to provide much-needed certainty to investors, with specific processes and options in the event of eventual grid connection detailed in advance. If social or political concerns of equity and fairness remain, then subsidies could be provided directly to micro-grid customers to balance their higher tariff and effectively match national tariff rates.

The second approach, alternatively, could be to maintain stricter national tariffs but ensure subsidies are provided to micro-grid developers to cover the difference between their presumed cost-reflective tariff and the national tariff that they are mandated to charge. As with approved tariffs, these subsidies must be guaranteed for the life of the system (or provided in full up-front) to boost investor confidence. Even in such cases, a business model that relies on production-based (e.g. per-kWh) subsidies for profitability will still be perceived as highly risky by investors, so a cost-reflective tariff that eliminates the risk of subsidy default or places subsidy default risk on customers rather than developers may be more attractive to investors. Subsidies that offer up-front repayment, rather than production (e.g., per-kWh) subsidies are typically more attractive for developers and investors and less burdensome to administer. However, upfront based subsidies can place more risk on the government (e.g. operators who default on projects before completion of their operational requirements) and can discourage later expansion to new customers without additional subsidies since the cost of providing that service is likely higher than the tariff allows. Hence a balance of both capital and output-based subsidies may be the best approach but also presents the greatest challenge to implement.

A third, more mixed approach could be to apply tariff and subsidy elements based on predetermined system criteria - for example, the use of capacity thresholds or community characteristics to classify which systems to regulate and to what degree. Perhaps the simplest way to categorize projects is by size and/or generation technology. In such an example, one might consider a scheme that bins projects into 
three discrete pools depending on the micro-grid size, with a slightly different regulatory framework for each. As one example:

\section{Small micro-grids (less than $\sim 100 \mathrm{~kW}$ )}

- No tariff regulation (e.g., developer-set tariff with no review/approval required).

- Tariffs based solely on willingness to pay and an implied customer-supplier agreement.

- Developers free to use innovative and flexible financing and payment schemes.

- Subsidies could be provided to the most economically disadvantaged to insure they are not priced out of receiving very basic energy services.

\section{Medium micro-grids ( 100 kW to $\sim 1 \mathrm{MW})$}

- A "lightly regulated" cost-reflective tariff may apply, such as the one described above.

- Tariffs reviewed and approved by regulator with minimally stringent criteria.

- Tariff approval guaranteed for the life of the project with clearly-defined compensation mechanism in the case of national grid encroachment.

- Cross-subsidies may be used to help offset costs for some customers (e.g., large/heavy consumers subsidize access for the most economically disadvantaged customers).

- A combination of production and up-front subsidies may be used to offset differences between rural and urban energy costs if there is a need to address concerns of "fairness."

\section{Large micro-grids (greater than $\sim 1 \mathrm{MW}$ )}

- A highly regulated framework in which national tariffs apply.

- Subsidies could be provided to developers to cover cost recovery gap, if needed.

- Cross-subsidies may be used to help offset micro-grid costs (e.g., grid-tied customers cross-subsidize cost of subsidies for micro-grid customers).

A three-tiered regulatory approach like the one presented here has proven successful in increasing the pace of micro-grid deployment in several instances - with Tanzania being perhaps the best-known example and Nigeria following suit — and elements of this approach could be replicated elsewhere. ${ }^{*}$ Of course, decisions about the particular design of such mixed-regulatory frameworks in other countries (e.g. which criteria and thresholds would be most applicable) must consider differing domestic factors such as the variety of community sizes and makeups and the extent of the existing grid and available resources.

Ultimately, it rests on policymakers and decision makers to determine the approach that will work best within their country's unique context. This begins with an honest assessment of which concerns receive the highest priority and the associated risks: keeping tariffs low and consistent across all customers at the risk of hindering the flow of private capital into electricity access projects, or allowing some customers to pay higher tariffs to attract necessary investment into electrification at the risk of upsetting some constituents. Even when charging rates above national tariffs, micro-grids typically still deliver overall cost savings to their customers while bringing the broader-reaching socioeconomic benefits of access to reliable electricity. Additionally, these decisions could also be coordinated with other relevant regulatory decisions such as land titling, tax registration, and import and local content requirements. Most

\footnotetext{
* An independent study by the International Renewable Energy Agency (IRENA) recently came to similar conclusions. See IRENA (2016), Policies and Regulations for Private Sector Renewable Energy Minigrids.
} 
importantly, any tariff-reform process will be more likely to have positive effects the more that relevant stakeholders (e.g. utilities, developers, investors, and customers) are consulted during the process.

Still, there is no perfect, one-size solution, and tariff methodologies are only one part of the picture. A host of other considerations, such as legal arrangements with utilities and distribution companies, variability in technology and fuel costs, political risks, and other macroeconomic factors can also affect the flow of investment into micro-grids. Increased flexibility, transparency and regional harmony across tariff frameworks - and how those frameworks apply to micro-grids - may be an important first step to encourage the wider deployment of micro-grids and accelerate the electrification of sub-Saharan Africa's diverse rural communities. 


\section{Appendix A: Cost Assumptions}

\begin{tabular}{|c|c|c|c|}
\hline & Data Required & Units & Current Assumptions \\
\hline \multirow{3}{*}{$\begin{array}{l}\text { Economic } \\
\text { parameters }\end{array}$} & Discount rate & $\%$ & $10 \%$ (real) \\
\hline & Fuel escalation rate & $\%$ & $3 \%$ (real) \\
\hline & Inflation & $\%$ & - \\
\hline \multirow{2}{*}{$\begin{array}{l}\text { PV panels + } \\
\text { structure }\end{array}$} & Total installed costs & USD/kW-DC & $800-1,200 / k W p$ \\
\hline & Useful life & years & 20 years \\
\hline \multirow{2}{*}{ Charge controller } & Total installed costs & USD/kW-DC & $200-400 / \mathrm{kW}$ \\
\hline & Useful life & years & 20 years \\
\hline \multirow{2}{*}{ Inverter } & Total installed costs & USD/kW-DC & $400-800 / \mathrm{kW}$ \\
\hline & Useful life & years & 10 years \\
\hline \multirow{4}{*}{$\begin{array}{l}\text { Storage (deep- } \\
\text { cycle lead acid) }\end{array}$} & Total installed costs & USD/kW-DC & $300-500 / \mathrm{kWh}$ \\
\hline & Useful life & years & 7 years \\
\hline & Minimum state of charge & $\%$ & $30 \%$ \\
\hline & Round-trip efficiency & $\%$ & $80 \%$ \\
\hline $\begin{array}{l}\text { Auxiliary costs } \\
\text { (wiring, breakers, } \\
\text { protection) }\end{array}$ & Total installed costs & USD/kW-DC & $200-400 / \mathrm{kW}$ \\
\hline $\begin{array}{l}\text { Power } \\
\text { house/container + } \\
\text { civil costs }\end{array}$ & Total installed costs & USD/kW-DC & $400-600 / \mathrm{kW}$ \\
\hline O\&M costs & $\begin{array}{l}\text { Fixed O\&M (excl. labor and } \\
\text { land) }\end{array}$ & USD/kW/year & $\begin{array}{l}2 \% \text { of capital } \\
\text { expenditures/year }\end{array}$ \\
\hline \multirow{10}{*}{$\begin{array}{l}\text { Diesel generator } \\
\text { specifications }\end{array}$} & Total installed costs & USD/kW & $400 / \mathrm{kW}$ \\
\hline & Fixed O\&M & USD/kW/year & 25/kW/year \\
\hline & Variable O\&M & USD/kWh & $0.023 / \mathrm{kWh}$ \\
\hline & Useful life & years & 10 years \\
\hline & \multirow{3}{*}{ Fuel cost } & \multirow{3}{*}{ USD/gallon } & 3.20/gallon (Tanzania) \\
\hline & & & 3.60/gallon (Ghana) \\
\hline & & & 4.40/gallon (Zambia) \\
\hline & Fuel consumption rate & gallons/kWh & 0.10 gallons/kWh \\
\hline & Minimum turndown & $\%$ & $30 \%$ \\
\hline & $\begin{array}{l}\text { Power house includes backup } \\
\text { genset? }\end{array}$ & yes/no & No \\
\hline
\end{tabular}




\begin{tabular}{|c|c|c|c|}
\hline & Data Required & Units & Current Assumptions \\
\hline \multirow{3}{*}{$\begin{array}{l}\text { Distribution } \\
\text { network }\end{array}$} & Total installed costs & USD/kW & $\begin{array}{l}\text { 20,000 for } 100 \\
\text { households }\end{array}$ \\
\hline & Fixed O\&M & USD/year & $\begin{array}{l}2 \% \text { of distribution capital } \\
\text { expenditures }\end{array}$ \\
\hline & Variable O\&M & USD/kWh & - \\
\hline \multirow{3}{*}{ Soft costs } & $\begin{array}{l}\text { Preoperating expenses (site } \\
\text { visits, design, licensing, } \\
\text { approvals, feasibility studies, } \\
\text { agreements, etc.) }\end{array}$ & USD/kW & $1,500 / \mathrm{kW}$ \\
\hline & $\begin{array}{l}\text { Labor costs } \\
\text { (customer relations, technical } \\
\text { support, revenue collection, } \\
\text { metering, etc.) }\end{array}$ & USD/year & $3,000 /$ year * \\
\hline & Land lease & USD/year & $800 /$ year * \\
\hline
\end{tabular}

* For the assumed system size of 100 households and 3 commercial entities with total use of $19,711 \mathrm{kWh} /$ year. 


\section{Appendix B: Load Profile Development}

Annual hourly electrical load data for micro-grids in rural sub-Saharan Africa is a key input into the REopt analysis. The micro-grids that were planned to be analyzed in REopt were assumed to have a mix of residential and commercial electrical loads. The NREL team, however, did not have hourly residential or commercial load data for rural sub-Saharan Africa, and a literature review was conducted to develop hourly micro-grid load profiles. Five papers ${ }^{32}$ were found that focused on residential loads in sub-Saharan Africa and two papers ${ }^{33}$ were found that focused on commercial loads. The major findings from this initial literature review include:

- Most rural homes have low-wattage devices that include electric lights, mobile phone chargers, and radios

- Televisions, DVD players, irons, and refrigerators are higher-wattage devices are not commonly found in rural homes, but households aspire to acquire these devices

- The typical shape of the hourly electrical load profiles for urban homes included a daytime electrical peak in the morning and an overall electrical peak in the evening

- Common rural business/community loads include water pumping for agriculture, milling related to agriculture, small shops (typically run out of houses), schools, and clinics.

Hourly electrical load profiles were developed for rural households and business/community entities using the information gathered from the literature review. The major assumptions used in making these hourly electrical load profiles include:

- The residential load is made up of 100 households

○ Each home uses $136 \mathrm{kWh} /$ year.

- The residential load is made up of the following low and high wattages devices:

- Low wattage:

- LED lighting (9 watts/unit)

- Mobile phone chargers (8 watts/unit)

○ Radios (15 watts/unit).

- High wattage:

○ Televisions (150 watts/unit)

- DVD players (35 watts/unit)

- Clothes irons (1000 watts/unit)

$\circ$ Refrigerators (average of 50 watts/unit when accounting for the compressing cycling on/off).

- The business/community load is made up of two small shops typically run out of houses and one school

○ $1,214 \mathrm{kWh} /$ year for a small shop

○ $1,961 \mathrm{kWh} /$ year for a school.

- For all the load profiles, it was assumed that there would be no variation from weekday to weekend and throughout the seasons. 
A ground-up approach based on the typical electrical devices found in homes was taken in estimating the magnitudes of the residential electrical load profiles. Similarly, typical electricity use of business/community entities in rural Africa were used to in estimating the magnitudes of the business/community entity electrical load profiles. The shape of the residential electrical load profile was generated by assuming the residences would use modest amounts of electricity during the daytime and the peak would occur in the evening. The shape of the business/community electrical load profile was generated assuming the business/community entities would use electricity throughout the daytime hours.

Once the shapes of the residential and business/community load profiles were generated, they were compared to 11 load profile shapes from actual micro-grids in rural Kenya and Tanzania, which were obtained from a recent journal article. ${ }^{34}$ The load profiles were normalized to the mean hourly load at each site to compare NREL's bottom-up load profile to load profiles from the 11 micro-grids in Kenya and Tanzania without having to worry about differences in the magnitude of the loads. Figure B-1 shows a comparison of the normalized electrical load profiles for micro-grids from the paper along with NREL's bottom-up load profile. The scenarios shown from the micro-grid paper include the average of all 11 micro-grids in Kenya and Tanzania along with the business-heavy and residential-heavy micro-grid load profile shapes taken from the micro-grid paper.

\section{Normalized Electrical Load Profile Shape Comparison}

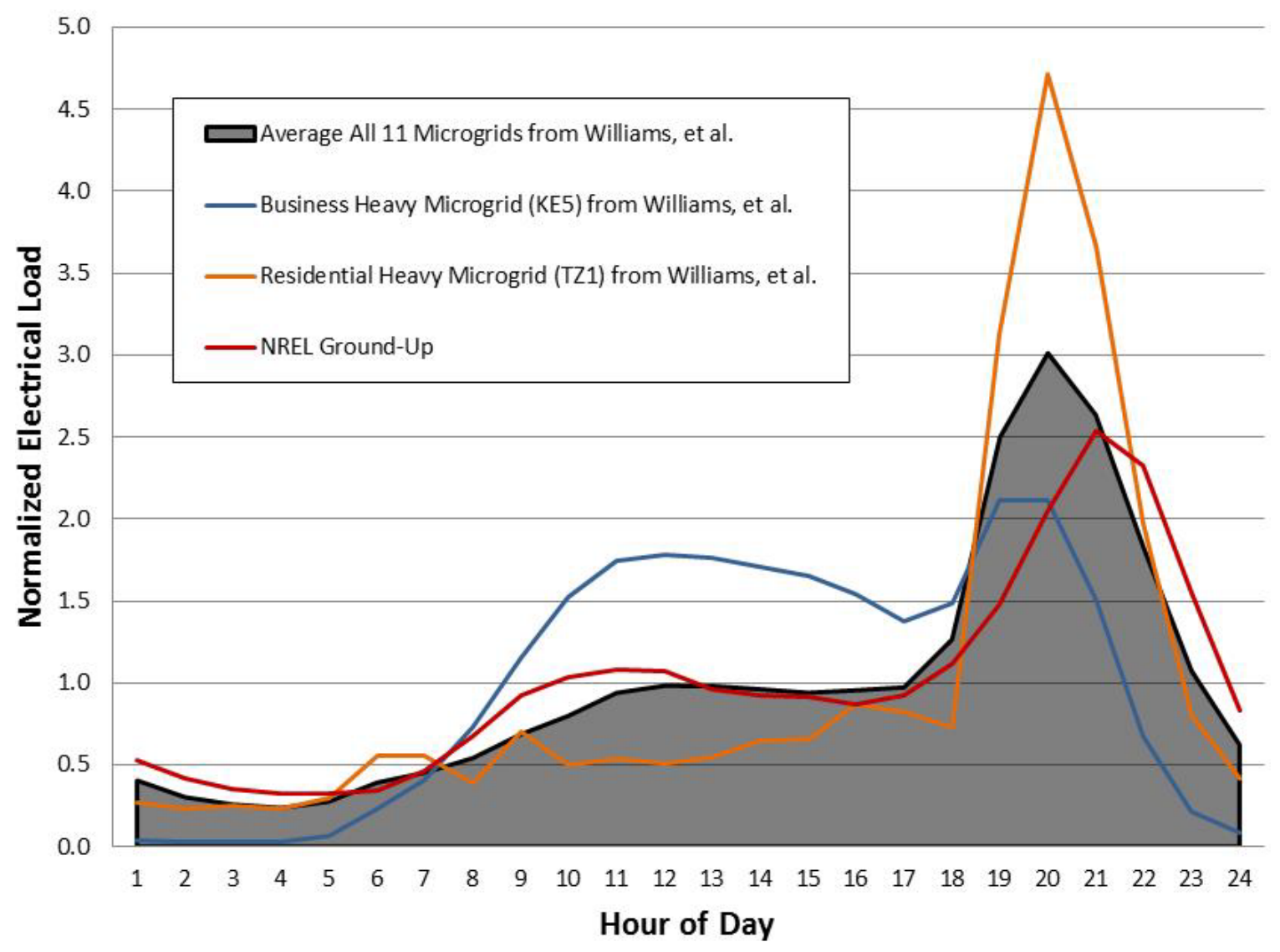

Figure B-1. Normalized electrical load profile comparison

As shown, the load profile shapes follow the same trend of peaking in the evening. The business-heavy profile has the smallest evening peak and the residential-heavy load profile has the highest peak. The NREL bottom-up load profile is similar to the load profiles from the paper, with the exception of the 
evening peak being shifted slightly to the later hours of the day. Each of these load profile shapes was analyzed in REopt.

\section{Appendix C: LCOE Sensitivity Analysis Using REopt}

To further understand the drivers behind cost-reflective tariffs, additional sensitivity analyses were performed using REopt around the following factors:

- Expected load profile - Analyzing the effect of varying the percent of commercial load vs. residential load on overall electricity cost when holding annual energy consumption constant. Increasing the percent of commercial entities in a village tends to shift loads to day time periods and reduce the evening peak (Figure $\mathrm{C}-1$ ).

- Quality of service-Analyzing the effects of reduced reliability on LCOE by using the proxy of percent of annual load served.

Figure C-1 shows the results of the additional sensitivity analyses for a solar-battery generation system as well as a diesel-only system in Tanzania. Each load profile simulated corresponds to a load shape depicted in Figure B-1, varying from the most residential-heavy to the most commercial-heavy profile.

As the percent of commercial load increases, overall electricity costs decline. The LCOE of solar-battery systems decreases due to the improved alignment between demand and PV generation. In the case of Tanzania, shifting from a residential-heavy consumption pattern to a business-dominated demand profile results in an average LCOE reduction of USD $0.19 / \mathrm{kWh}$. The LCOE of diesel-based systems also decreases because reduced peak loads allow for smaller generators. Here, LCOE decreases by up to USD $0.03 / \mathrm{kWh}$ when moving from a residential-heavy consumption profile to a commercial-heavy consumption profile.

Figure C-1 also shows the impact of reduced quality of service on LCOE. For solar-battery systems, costs decline steeply as soon as the requirement to meet $100 \%$ of the load is relaxed. The LCOE drops by approximately USD $0.17 / \mathrm{kWh}$ when the system is only required to meet $95 \%$ of the annual load instead of $100 \%$. Meeting the last $5 \%$ of load causes costs to spike, as installed capacities must be significantly oversized to carry the system through intermittent periods of inclement weather. The drop in LCOE levels off to less than USD $0.04 / \mathrm{kWh}$ for each additional 5\% decrease in load served.

Reduced electricity delivery reliability also results in lower LCOEs for the diesel-only system. However, reductions here are modest, as cost savings are only achieved through decreased fuel usage. Diesel generators are still sized to meet the expected system peak regardless of the target level of reliability. The LCOE of the diesel-only system declines consistently by USD $0.02 / \mathrm{kWh}$ for every $5 \%$ decrease in annual load served. 
Solar-battery system

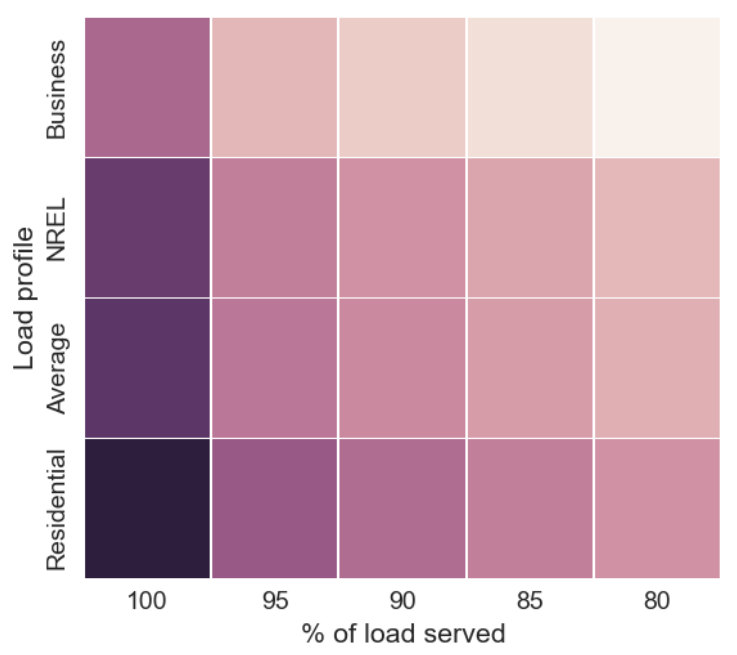

Diesel-only system

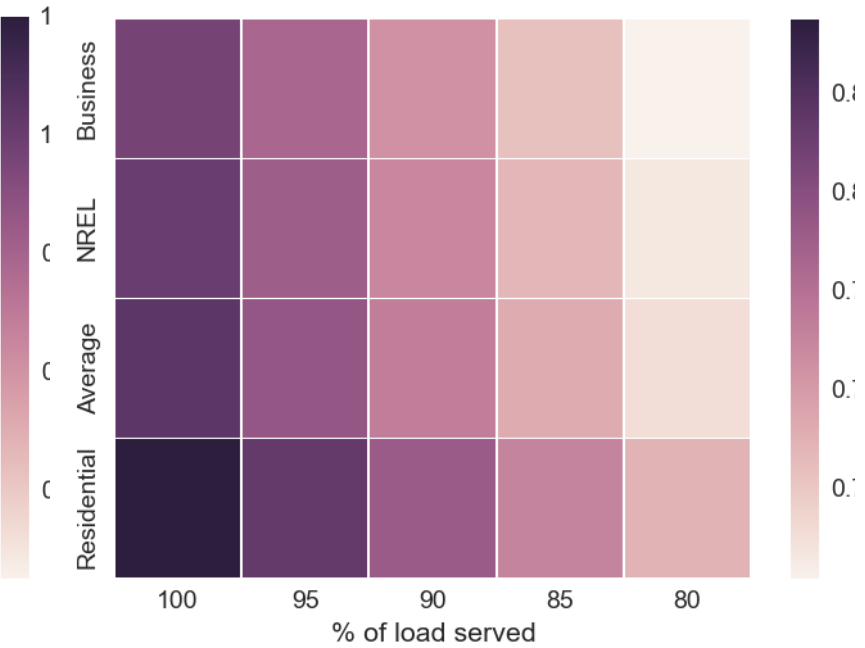

Figure C-1. The impact of load shapes and quality of service on micro-grid LCOE (Tanzania example) 


\section{References}

${ }^{1}$ International Energy Agency, Energy for All: Financing Access for the Poor (Paris: International Energy Agency, 2011), http://www.worldenergyoutlook.org/media/weowebsite/2011/weo2011 energy for all.pdf.

${ }^{2}$ Ibid.

${ }^{3}$ Terri Walters, Sean Esterly, Sadie Cox, Tim Reber, and Neha Rai, Policies to Spur Energy Access, Volume 1: Engaging the Private Sector in Expanding Access to Electricity, NREL/TP-7A4064460 (Golden, CO: Clean Energy Solutions Center, 2015), http://www.nrel.gov/docs/fy15osti/64460-1.pdf.

${ }^{4}$ Ian Baring-Gould, Kari Burman, Mohit Singh, Sean Esterly, Rose Mutiso, and Caroline McGregor, Quality Assurance Framework for Mini-Grids, NREL/TP-5000-67374 (Golden, CO: National Renewable Energy Laboratory, 2016), http://www.nrel.gov/docs/fy17osti/67374.pdf.

${ }^{5}$ Inferred from personal communications with multiple African policymakers and experts.

${ }^{6}$ International Finance Corporation, Operational and Financial Performance of Mini-Grid DESCOs: Findings and Insights from Pioneer Benchmarking of this Emerging Sector (Washington, D.C.: World Bank Group, 2017), https://gallery.mailchimp.com/39ef5953cb296ad051b58bd59/files/101a92a2-4c61-46ac-b142$\underline{\text { 80df08f3375e/IFC_Minigrids_Benchmarking_Report_Single_Pages_January_2017.pdf. }}$

${ }^{7}$ Franz, Michael, Nico Peterschmidt, Michael Rohrer, and Bozhil Kodev, Minigrid Policy Toolkit: Policy and Business Frameworks for Successful Minigrid Roll-outs. (Germany: Africa-EU Renewable Energy Cooperation Programme (RECP) and the European Union Energy Initiative Partnership Dialogue Facility (EUEI PDF), 2014). https://collaboration.worldbank.org/docs/DOC-10872

${ }^{8}$ PwC, A New Africa Energy World: A More Positive Power Utilities Outlook, Africa Power \& Utilities Sector Survey (London: PwC, 2015), https://www.pwc.com/gx/en/utilities/publications/assets/pwc-africa-power-utilities-survey.pdf.

${ }^{9}$ Power Africa Transactions and Reforms Program (PATRP), Ghana Off-Grid Policy and Regulatory Framework Assessment Report (Washington, D.C.: Power Africa, 2017).

${ }^{10}$ See Abdur Rahman Alfa Shaban, "Tanzania President Reverses Utility Tariff Hike, Fires Head of Power Firm," Africa News, January 2, 2017, http://www.africanews.com/2017/01/02/tanzaniapresident-reverses-utility-tariff-hike-fires-head-of-power-firm/.

${ }^{11}$ Energy and Water Utilities Regulatory Authority of Tanzania, “Appendix 3B: Detailed tariff calculations for the year 2016 for the sale of electricity to the mini-grids in Tanzania under standardized small power purchase agreements" (December 2015), http://144.76.33.232/wpcontent/uploads/2015/12/APPENDIX-3B SPPT-Computations Mini-Grid 10Dec2015.pdf; Clean Energy Solutions Center, "Mini-grids for Energy Access in Sub-Saharan Africa: Status and Lessons from Tanzania" (Webinar, May 31, 2016), https://cleanenergysolutions.org/training/mini-grids-energy-access-tanzania. 
${ }^{12}$ Economic Consulting Associates, “Mini-Grids: Are Cost-Reflective Tariffs Necessary?” ECA Viewpoint, February 2017, http://www.eca-uk.com/2017/02/22/mini-grids-are-cost-reflectivetariffs-necessary/.

${ }^{13}$ International Renewable Energy Agency (IRENA), Policies and Regulations for Private Sector Renewable Energy Mini-grids. (Abu Dhabi: IRENA, September 2016).

${ }^{14}$ Hivos International, "Zambia Energy Profile" (no date), https://www.hivos.org/sites/default/files/zambia profile.pdf; Mildred Katongo, "Mabumba Commissions a K11 Million Grid Extension Project in Mpongwe" (Lukasa Times, July 23, 2017), https://www.lusakatimes.com/2017/07/23/mabumba-commissions-k11-million-grid-extensionproject-mpongwe/; European Commission International Cooperation and Development, "Construction of Two-Grid Extension Projects in Kaoma and Mumbwa Districts in Zambia," https://ec.europa.eu/europeaid/projects/construction-two-grid-extension-projects-kaoma-andmumbwa-districts-zambia en; Gakenke, "Africa Unplugged” (The Economist, October 29, 2016), https://www.economist.com/news/middle-east-and-africa/21709297-small-scale-solarpower-surging-ahead-africa-unplugged; Josh Agenbroad, Kelly Carlin, Stephen Doig, Claire Henly, and Eric Wanless, Energy Within Reach: Growing the Minigrid Market in Sub-Saharan Africa, (Boulder, CO: Rocky Mountain Institute, 2017), www.rmi.org/energy within_reach.

${ }^{15}$ Baring-Gould et al., Quality Assurance Framework for Mini-Grids.

${ }^{16}$ More information available at: https://REopt.nrel.gov/

${ }^{17}$ Agenbroad et al., Energy Within Reach; International Renewable Energy Agency (IRENA), Solar PV in Africa: Costs and Markets (Abu Dhabi: International Renewable Energy Agency, 2016). https://www.irena.org/DocumentDownloads/Publications/IRENA_Solar_PV_Costs_Africa_2016. pdf.

${ }^{18}$ IRENA, Solar PV in Africa.

${ }^{19}$ Data from https://energyplus.net/weather.

${ }^{20}$ Data from http://www.ewura.go.tz/?cat=9.

${ }^{21}$ Data from http://www.npa.gov.gh/downloads/indicative-prices.

${ }^{22}$ Data from http://www.erb.org.zm/content.php?viewpage=tfpg.

${ }^{23}$ Nathaniel J. Williams, Paulina Jaramillo, Benjamin Cornell, Isaiah Lyons-Galante, and Ella Wynn, "Load Characteristics of East African Micro-grids" (paper presented at IEEE Power \& Energy Society PowerAfrica, Accra, Ghana, June 27-30, 2017), http://ieeexplore.ieee.org/document/7991230/.

${ }^{24}$ Ibid.

${ }^{25}$ International Finance Corporation, Operational and Financial Performance of Mini-Grid DESCOs. 
${ }^{26}$ PATRP, Ghana Off-Grid Policy and Regulatory Framework Assessment Report.

27 "Government Limits the Amount of Subsidies Given to TANESCO to 0.3 Percent of GDP," Corporate Digest, 2013, http://www.corporate-digest.com/index.php/government-has-committed-to-limitthe-amount-of-subsidies-given-to-tanesco-to-03-percent-of-gdp.

${ }^{28}$ Clean Energy Solutions Center, "Mini-Grids for Energy Access in Sub-Saharan Africa: Status and Lessons from Tanzania," webinar, May 31, 2016, https://cleanenergysolutions.org/training/minigrids-energy-access-tanzania.

29 “Current ZESCO Tariffs,” accessed August 1, 2017, http://www.zesco.co.zm/customerCare/tariffs.

${ }^{30}$ Ibid.

${ }^{31}$ Agenbroad et al., Energy Within Reach.

${ }^{32}$ Kenneth Lee, Edward Miguel, and Catherine Wolfram, “Appliance Ownership and Aspirations among Electric Grid and Home Solar Households in Rural Kenya," American Economic Review: Papers \& Proceedings 106:5(2009): 89-94, http://dx.doi.org/10.1257/aer.p20161097; Chukwunonso Chidebell Emordi, "A Complex Systems Approach to Energy Poverty in sub-Saharan Africa: Nigeria as a Case Study" (PhD diss., Arizona State University, 2015); Candia Drazu, Mark Olweny, and Goodman Kazoora, "Household Energy Use in Uganda: Existing Sources, Consumption, and Future Challenges" (Living and Learning: Research for a Better Built Environment: $49^{\text {th }}$ International Conference of the Architectural Science Association, 2015), 352361; M.B. Manjia, F. H. Abanda, and C. Pettang, "Household Energy Appliance in Cameroon" (Environmental Management and Sustainable Development 2015), 73-74; Martin Chanza, Pranesh Ramjith, and Gerard Van Harmelen, "Forecasting Domestic Hourly Load Profiles Using Vector Regressions" (IEEE Domestic Use of Energy Conference, 2013).

${ }^{33}$ Sudeshna Ghosh Banerjee, Kabir Malik, Andrew Tipping, Juliette Besnard, and John Nash, Double Dividend: Power and Agriculture Nexus in Sub-Saharan Africa (Washington, D.C.: International Bank for Reconstruction and Development/The World Bank, 2017); A.S. Oladeji and B.F. Sule, "Electrical Load Survey and Forecast For Decentralized Hybrid Power System at Elebu, Kwara State, Nigeria" (Nigerian Journal of Technology, 2015) 591-598.

${ }^{34}$ Williams et al., "Load Characteristics of East African Micro-grids." 